\title{
ThroughBlue: A support group for women affected by depression
}

Trish McBride in association with Jane Fuller

Trish McBride is a counsellor in private practice and has co-facilitated ThroughBlue for six years. She can be contacted at mcbride@paradise.net.nz. Jane Fuller is a counsellor with Conversations (formerly Wellington People's Centre), and has co-facilitated ThroughBlue for 12 years.

\section{Abstract}

Recent US research has validated the benefits and therapeutic value of peer support groups as a treatment component for depression, as has a 2008 Australian study of a women's mental health support group. As facilitators working weekly with ThroughBlue, a support group of women who have experience of depression, we had already discovered the truth of their findings. This paper is a description of the way this Wellington group works, and may be of use to others looking to set up or facilitate similar groups elsewhere.

\section{Introduction}

The writers co-facilitate ThroughBlue, a weekly support group for women with experience of depression. We wish in this paper to connect the experiences of the women and our own, with the research results of a US study comparing the benefits and therapeutic value of peer support groups with other treatments for depression, and with Australian social worker Dorothy Scott's 2008 paper describing the success of a support group for women who had had experienced postpartum psychosis. We will outline the history and organisation of the group, modalities used and outcomes for the women.

\section{US researchers say...}

Based on the pooled results from published randomized controlled trials, peer support interventions for depression result in greater improvement in depression symptoms than usual care and may have similar efficacy to group cognitive behavioral therapy. There was wide variability in the patient populations and peer interventions studied; therefore, clinical trials capable of determining the optimal dose and type of peer relationships, and likely responders to peer support, are needed. Given the high level of functional burden imposed by depression worldwide, peer support for depression should also be studied as a potentially low-cost intervention in primary care or other settings where more established but costly depression services are unavailable (Pfeiffer, Heisler, Piette, Rogers, \& Valenstein, 2010).

And Scott (2008, p. 205):

If one considers the social determinants of health, then the need to increase social support at a population level is clear, given that social support is a strong protective factor. Groupwork may therefore be a powerful prevention strategy, not just a remedial intervention. 


\section{The ThroughBlue women say...}

When some members were asked in October 2011 what had changed for them since they began attending the group, these were their verbatim responses. They have offered them for publication, along with their own names:

I am more self-aware and able to manage. The weekly group gives focus and a 'go to' point when all else seems unmanageable. There is incredible unconditional support from others. It is the only place in this world where I can say how it really is for me. It is a source of learning strategies that help me live a real life in the real world. Caring for each other in the group gives me a sense of purpose, and meaning to my own suffering of depression (Jane).

ThroughBlue helps me getting through a rough patch when I can't afford counselling. It prevents me from going back into deep depression, so I am able to care for our children again. If it wasn't for ThroughBlue the Public Health System would have to 'pick up the pieces' (Heidrun).

I am more honest with myself. And more conscious of my wellness. I develop strategies to cope with my unwellness. It is a connection with a group of people who suffer with mental issues. I have developed empathy and skills in listening to other people's stories (Laureen).

I am now better able to lessen my burden, because the group gives me a safe place to share what's really going on for me. I feel less alone and better supported. I can be gentler on myself for my mistakes, and can move on from them and put them behind me more readily. I have a reliable place to check in/return to, whereas previously I would not have known where to turn. I am not as isolated as I was. I spend less time feeling without hope. I enjoy life a little and can usually face each day fairly 'normally' where before I was a mess, could not imagine a way forward and did not want to. I only occasionally think about suicide where before it was all the time (Amanda).

ThroughBlue weekly meeting is my personal lifeline. It provides continuous support and I appreciate the safety. People's stories are an inspiration and a comfort to me, and because my own burden is shared amongst others it allows me to manage it (Sara).

There is comfort in knowing there are others like me, who understand what I am going through. And knowing every week I can come somewhere safe to relax, find help and a break from the world, a focus. Care of others, hearing and following stories, having empathy - something I lost with my depression. New friends. Strength in knowing I have a support base. I can use this group as a benchmark to monitor my changes, knowing there are people also seeing my progress. I learn new tools from others' experiences, suggestions, groundings and the topics. By connecting with others I am more aware of my feelings. I can share ideas with people to see how they have coped/used similar techniques. I am so much better than I was. I love this group!! (Susanna).

\section{Herstory}

ThroughBlue began in April 1997 with the name of Depression Support Group for Women at the Wellington Women's Centre under the auspices of the Women's Health Collective (WHC) on the initiative of the counsellor, Lora Mountjoy, who was working as coordinator there with Nikki Saffery. They applied for funding for the group. A three month pilot funding grant of $\$ 2098.13$ was given by the Community Development section of Wellington City Council (WCC). The WHC - Nikki and newer coordinator Robyn Goldsmith - maintained the group for eight years by making applications to funders such as WCC, Community 
Trust and the Box Trust. When they lost the use of the building leased from the WCC in May 2005, they moved to another space which could not accommodate the Depression Support Group, so it stopped meeting.

However a core group of the women who had attended valued the group experience so much that they formed a management committee to restart the group with a new name: ThroughBlue. They applied for and acquired funding, so the re-formed group began in October 2005 with the two facilitators, who had taken over in 2000. One of them has been with the group since then, and Trish (author) replaced the other in 2006. The committee agreed to apply for grants from various charitable bodies to raise funds to cover costs running the group. They went on to register ThroughBlue as an incorporated society and also a registered charity to aid grant applications and to establish clarity for its aims, processes and outcomes.

\section{Management}

The ThroughBlue Board submits an average of eight grant applications in any one year, about half of which are successful. These grants, along with occasional donations from group members or former members, have enabled the group to run successfully over the years, with one brief hiatus in 2006 due to a funding shortfall. The costs are rent, payment of two counsellors (including regular supervision) and a childcare person, tea, coffee and biscuits for during the break, and administration costs. The women are asked to contribute $\$ 5$ per session. This is negotiable, and sometimes WINZ is prepared to meet this cost. A contract has recently been produced to formalise relationships with the two counsellors and the child-care worker.

Ownership of the group by the women themselves has been an important development, and has contributed to their developing a range of skills, as well as contributing their voluntary time to a group that benefits others. As with any community group that depends on funding from grants the situation is often tight, but has been sustained through the generosity of various charitable trusts.

\section{Pamphlet}

After an occasion when there were expectations of continuing care from the facilitators that we were contractually and personally unable to meet, we put together an information pamphlet. This was also a step towards increasingly professional presentation of the group's functions and parameters. A copy of this is given to each woman who comes for the first time. It has a panel to be returned with contact information, including their GP, counsellor and emergency support person.

The pamphlet features a stylised ponga seen from above with new fronds still tightly furled, others open, on a pale blue background, an image created by Wellingtonian Fyvie Murray as a quilt. We were delighted to have her permission to use it. It symbolises so much of what happens at ThroughBlue. Women come tightly curled up and gradually relax and open to their full potential with the experience of shared and sharing life.

As well as time and place details, the pamphlet contains the following information: 


\begin{abstract}
Depression is a difficult and painful illness which is often very isolating. By coming to the group you have taken an important step towards healing yourself. We hope you will find ThroughBlue a safe environment where you can speak your own truth, feel understood and valued and grow in self-awareness. We suggest coming 3-4 times before deciding whether this group will be useful to you.
\end{abstract}

What ThroughBlue offers

Support and companionship as you work on your depression

Education in managing depression

Low cost ( $\$ 5$ negotiable)

Non-religious, inclusive support

Come when it suits - though there are benefits to attending regularly

Confidentiality as agreed

Free child-care

Participants may choose to have contact with each other outside the group

We cannot offer:

Counselling/therapy - you will probably need your own therapist to do deeper work on issues that arise in the group

Continued support from the facilitators after the session

Group Agreement

Please arrive by 12.25 for 12.30 start

Please turn off mobiles

Advise facilitators if you will leave early

Listen with respect and warmth

You can always pass if you don't want to speak

Use 'I' statements, share your own experience

No interrupting or advice-giving

No put-downs of self or others

If something bothers you in the group, discuss with the person or a facilitator

If you feel disturbed or distressed at the end of the group talk to a facilitator before leaving to develop a plan

The structure of the session as outlined below is also on the pamphlet.

\title{
Session structure
}

There are two halves to the two hour session. The facilitators see the room is prepared with a dozen chairs round a table, the group agreement poster, the pamphlet holder, the tissues, and drink gear and biscuits. We start promptly at $12.30 \mathrm{pm}$. Coming late is actively discouraged as it is difficult to feel safe in sharing when there are late-comers disrupting the flow.

One facilitator leads the first half of the session and the other the second. We invite each woman to share a highlight from the week, whether they managed the goal they may have set themselves the previous week, and generally how they are. For the last four years we have, after consultation with group members and Management Board, limited each woman's speaking time to five minutes. We call on this if there are eight or more present. While there was some initial reluctance to be 'limited', it is now generally appreciated. It means there is always time to offer the quiet and withdrawn ones as their entitlement, and is a containment for those who may get started and be unable to stop. It also encourages some 
reflection before the group, and some selection of what is really important to share. If necessary, people are given a gentle invitation to wind up what they have to say. And of course there are times when crises need more attention, so there is some discretionary flexibility as appropriate. When everyone has shared, the same facilitator leads a 3-5 minute grounding/ meditation / visualisation exercise.

There is a break of about 10 minutes. Tea, coffee and biscuits are available. Occasionally, one of the women will bring some baking or other goodies, which are always appreciated and 'giving' has its own therapeutic value.

The other facilitator then leads the second half of the programme, the educational topic time. The closing round occupies the last 10 minutes. The invitation to each is to set a personal goal, if they wish (small, specific, achievable), which is recorded, to identify something that they are looking forward to, and what they will take away from being with the group that day. We finish at $2.30 \mathrm{pm}$ sharp.

The facilitators pack away the resources. Very occasionally there will be someone who is significantly distressed and we spend time ensuring safety, and plans for support. Part of the group agreement is not to leave feeling distressed, but to check in with the facilitators. On the rare occasions when it has been necessary, other group members have volunteered to take someone home or to their doctor. We have asked then to be contacted by the person and the helper to ensure a safe hand-over.

No notes are kept other than a record of who attended, the topic that was discussed and the goals the women may have chosen to set themselves - another difference between a support group and a therapy group. We facilitators debrief after each session by sharing our observations and reflections by phone.

\section{Topics}

In the early days there were about a dozen topics that were more or less rotated. Recently there has been a much wider range, usually selected by the facilitators on the basis of the previous weeks' conversations, sometimes suggested by the participants. Recent topics have been conflict and guilt, Just Observe Your Depression (George Sweet), grief, entitlements, impulse management and sleep. General headings are self-care, personal growth, families and relationships. The session pattern is for some minimal input from the facilitators and an open, flowing conversation amongst the group. Sometimes art work or personal writing is suggested, with an option to share these.

One exercise was offering the group a modified Myers Briggs personality type process, to affirm differences and gifts. Trish, an INFJ herself, had a sense that a number of the group could share this unusual (about $1 \%$ of the general population) profile. And indeed five of the nine present that day checked as INFJ. Unsurprisingly, people with this profile often feel they don't fit in the world, that it is a mystery, and that no one 'gets them', easily internalised as 'It's all my fault, there's something wrong with me'. There is no initial awareness of sensitivities not shared by the rest of the world. All of which adds up to a significant factor in some people's depression. Jane as an ENFP facilitator is now more aware of J people's need for clear and definite instructions with topic-time tasks. The group has on occasion 
given us appreciative feedback around our different styles of working with them. A topic Jane presented that has been significant is focusing on the Present Moment using breathing techniques to let go of past and future. She now incorporates more breathing techniques in the grounding time. She has herself experienced the benefits of breathing tools in dealing with anxiety and encourages the women to use these for themselves.

\section{Intake/referrals}

Some women are referred by counsellors, GPs or other professionals, but most over the last few years seem to come via the internet, where they have looked for 'depression support, Wellington'. The information there offers basic ThroughBlue information, www. throughblue.org.nz and a contact number. There is also a link from the Wellington City Council Community services website. While prior contact with a facilitator is preferred, women do sometimes arrive unannounced, which almost invariably works well. Rare mismatches usually mean the person simply opts out. In the last year 17 women have come to the group for the first time, and 33 individual women in total have attended.

\section{Demographics}

Over the years, the ages of participants have ranged from 19 to 83 . There is a significant proportion in their mid to late 30 s. The current age range is $26-55$. Of the very regular 10 or so attenders, five are in long-term partnerships, the rest single.

\section{Facilitators' assumptions}

That depression is there for a reason; that huge energy goes into hiding it and 'acting normal'; that learning to 'be real' in a safe environment can be a prelude to 'being real' in significant relationships and the wider world; that the isolation of depression is challenged by being with others in the same situation; that coping strategies can be shared; that learning and growth will occur; that medication is sometimes necessary and personal counselling/therapy can be invaluable; that feelings/emotions are generally being 'depressed' (George Sweet); that the shift from reliance on external to internal authority is one of the most significant tasks of adulthood, if it hasn't been accomplished earlier; that respect for one's own inner processes can be learned.

\section{Modalities}

This is a peer support group, not a therapy group, so interventions by facilitators are therefore less probing than in a counselling session. Our personal styles and preferences are relevant. In the group's earlier days there was significant emphasis on Cognitive Behavioural Therapy (CBT). Recently we have focused more on Humanist/Existential work with a psychodynamic understanding, some narrative input and a feminist analysis. CBT is used as appropriate. The women are generally more in need of learning to feel and express emotions, than learning to think. While the group has so far been mostly Pakeha, we have used Mason Durie's Te Whare Tapa Wha model (Durie, 1998), a holistic Maori mental health model which compares good health to the four sides of a house, requiring a balance between spirituality (taha wairua), intellect and emotions (taha hinengaro), the human body (taha tinana) and the extended family (taha whänau). Attention must be paid to all four of these 
aspects of life. Spirituality in general or religious beliefs and experiences are not generally part of the Pakeha mental health framework, but can be very pertinent to mental health as either sources of, or impediments to, healing. Rawiri Evans, team leader at Community Mental Health and Addiction Services, Lower Hutt, recently told how he'd been asked by a psychiatrist 'How do we get it right for Maori?' and had responded 'When you do it right for Maori, you'll be doing it right for everyone!'

\section{Clinical}

Depression rarely appears on its own. Frequently there is a background of abuse of some sort, and it is often part of a complex web involving anxiety, sleep and eating disorders which often produce an additional burden of shame, guilt and self-condemnation. Personal therapy and medication are probably going to be necessary as well as the support group. Work in the group can lead to a more respectful and compassionate approach to themselves, with significant stress reduction.

Suicidality is both mentionable and assessed. On occasion women have been invited to make a safety contract with the group. Regrettably, the rare need to contact the CAT Team has not led to interventions that most of those women found helpful. Also, as the group is held on a Friday afternoon, accessing emergency medical appointments can be difficult. It is then back on the 'community' to manage crises. To date this has sufficed.

Medication is a significant issue for almost all the group. The women often compare notes about the effectiveness or otherwise and side-effects of their different regimes. Beyond the provision of a venue for these conversations, this is something we leave entirely to them and their doctors / psychiatrists. Adequate support and monitoring from these professionals are necessary, but not always provided. As counsellors we believe that medication alone is not going to resolve depression, and sometimes hear with a degree of alarm the medication cocktails that some are or have been on for many years. Changes in medication often create significant hiccups in life as it can be a period of several weeks between weaning from one until the new one becomes effective. The group can be a valuable support during these interludes.

\section{Observations}

As facilitators, we participated in a psychodrama-based training programme in 2009 to enhance our awareness of group dynamics. We became more aware of group norms and a socio-metric perspective of our work. We have observed several shifts in group norms over the last few years. One is in the amount of interaction between group members outside the sessions. The shifts have been from 'none apparent', to 'some for some people, but not to be mentioned in the group', to the present situation where there are some good friendships, social interactions, and concern for and contact with those who are struggling - a genuine little community beyond the meetings and which is welcoming to newcomers.

Another shift in norms has been the increased willingness of members to express any distress or anger triggered in the group, and on occasion to challenge the facilitators. This has needed a great deal of encouragement as the fear involved is significant. As are the benefits! Relationships can survive disagreements! The group provides a safe place for women to practise asking for what they want and expressing feelings. 
One of the surprises for two non-cat-owning facilitators is the power of cats to sustain and comfort their owners. The love of cats is also a bond between members who may not have much else in common. Cat photos can be a source of pleasure to several members. One woman who has felt suicidal at times said when she began at the group that she was kept alive by her two older cats. They have now died, but she has a kitten in her life that is a sign of hope for the future. When asked recently during a very low patch whether she needed to make a safety contract with the group, she replied she had a contract with her cat. Others, too, say their cats keep them alive.

\section{Outcomes}

A few members of the group have been coming for many years, even since the group began. Others are more recent. If they persist, within a few months they are saying things like:

This group is my life-line.

If it wasn't for this group, my husband would no longer have a wife or my children a mother.

This is a sanctuary.

I thought I was the only person in the world who feels like that.

Depression is such an invisible illness! After a couple of years in the group, one woman decided to struggle no longer with hiding her depression, and recently showed us all a tattoo she'd just had done. Here are her words about this experience:

I chose to get this tattoo for a number of reasons, the main ones being that I feel as though I am permanently marked by depression (and anxiety), but that it has been a hidden ailment. I wanted something that would be subtly visible, so I had it placed over the cut I once made on my wrist. I believe that depression has permanently changed me and I wanted to have something permanent to remind me of the journey I am travelling. It is a difficult journey, and I have sustained numerous invisible wounds along the way. The tattoo is a representation in Chinese characters of the scars left by those wounds, but also a reminder that I have survived them and become a stronger, more aware person because of them. I have promised myself that I will tell whoever asks about my tattoo what it means and why I have it, because I am tired of being unreal about my depression.

The first person to ask about it and receive the explanation responded, 'Wow - you and John Kirwan!' How honouring of both the former All Black and of the woman. Both had spoken out to educate the community.

Women have regained a sense of self, connection with others. There have been returns to the workforce, improved well-being and family relationships, moves out of abusive relationships and work situations. To hear from anyone 'I've felt happy', 'I've had a good week' or 'I said 'No, I won' $t$ ' occasions a celebration - and is an encouragement for the others!

Returning to the workforce presents a significant challenge around disclosure - or not - of mental health history to potential employers. One former group member was delighted to discover that hers actually became an asset, a qualification. She became a valued full-time support worker for other mental health consumers, having begun with part-time hours. As the stigma of mental illness reduces somewhat in the community, hopefully this will become less of an issue for both employers and job seekers. Currently it is still significant and each woman has to make her own decisions around this. 


\section{Passing it on}

A development in 2012 was the planning and organisation by the three group members who are also on the Board of an extra eight-week course for women with depression, facilitated by the same two counsellors. They hoped that another dozen women might generate their own ongoing group and were prepared to offer mentoring in doing so. This involved a considerable number of voluntary hours and use of their administrative skills. Outcomes similar to both the 'parent' ThroughBlue Group and to the Australian group were quickly evident: in-depth sharing, the evaporation of isolation, bonding, growth in trust, new hope. (Scott, 2008). Another course is planned for early 2013.

\section{Recent research}

The US researchers quoted at the beginning of the paper cite the following:

According to her (Dennis's) analysis, peer support interventions may decrease isolation (direct effect), reduce the impact of stressors (buffering effect), increase sharing of health and self-management information (direct effect), and provide positive role modeling (mediating effect). Yalom describes peer support groups as having many similar features to group psychotherapy: altruism, cohesiveness, universality, imitative behavior, instillation of hope, and catharsis. Peer support programs may also empower patients to play a more active role in their own self-care (Pfeiffer, et al., 2011).

They conclude:

Programs in which patients and volunteers share information were found to reduce symptoms of depression better than traditional care alone and were about as effective as cognitive behavioral therapy, researchers found after analysing ten randomised trials of peer support interventions for depression dating from 1987 to 2009 (Pfeiffer, et al., 2011).

\section{Conclusion}

For the facilitators, each session is an intensely rewarding and privileged experience. Along with the real and on-going suffering of depression, we see significant courage, the growth of acceptance of, and compassion for, self and others, and willingness to experiment with changes of thinking and behaviours. And as well as the tears, there is often some great humour and laughter! (Scott, 2008). We think of this work as soul-mending. Our vision for the group members is that they be well supported on their journeys to human wholeness, that they gain experiences and tools to help them heal themselves over time, that they can practise being who they truly are. It is satisfying to see the outcomes of clinical research overseas match our experience and that of the women of ThroughBlue. We believe that the peer support model of treatment for depression is worthy of medical recognition in Aotearoa New Zealand, and that appropriate permanent funding support should be made available as a cost-effective treatment for a regrettably common illness.

\section{References}

Dennis, C. L. (2003). Peer support within a health care context: A concept analysis. International Journal of Nursing Studies, 40, 321-332.

Durie, M. (1998). Whaiora: Maori health development, pp. 68-74. Auckland: Oxford University Press. 
Evans, R. (2010). Ki te Marama i te tangata me märama hoki i tana ao: Are cultural competencies critical for Maori mental health practitioners? Unpublished MPhil thesis. Massey University: Palmerston North.

Kirwan, J. (2010). All Blacks don't cry: A story of hope. New Zealand: Penguin.

Pfeiffer, P. N., Heisler, M., Piette, J. D., Rogers, M. A. M., \& Valenstein, M. (2011). Efficacy of peer support interventions for depression: A meta-analysis. General Hospital Psychiatry. 33(1), 29-36, available online at www. sciencedirect.com.

Scott, D. (2008). From clinic to community: The evolution of a group for women with postpartum mental illness. Australian Social Work, 61(3), 197-206.

Sweet, G. (2009). Counselling Resources. CD.

Yalom, I. D. (2005). Theory and practice of group psychotherapy, 5th ed. 